\title{
Impact of processing degree on fermentation profile and chemopreventive effects of oat and waxy barley in LT97 colon adenoma cells
}

\author{
W. Schlörmann ${ }^{1,2} \cdot$ F. Keller $^{1} \cdot$ S. Zetzmann ${ }^{1} \cdot$ S. Lorkowski ${ }^{2,3} \cdot$ C. Dawczynski $^{2,4} \cdot$ M. Glei $^{1,2}$
}

Received: 14 August 2020 / Revised: 29 October 2020 / Accepted: 31 October 2020 / Published online: 25 November 2020

(c) The Author(s) 2020

\begin{abstract}
The chemopreventive effects of $\beta$-glucan-rich cereals such as oat and barley (beta®barley) have been examined previously, but studies comparing fermentation characteristics and chemopreventive effects of oat and barley of different processing stages are rare. Therefore, the present study aims at investigating the fermentation end points ( $\mathrm{pH}$ values, concentrations of shortchain fatty acids (SCFA) and ammonia) in fermentation supernatants (FS) obtained from differently processed oat and barley samples (kernels, thick and thin flakes). Chemopreventive effects of FS, such as growth inhibition, apoptosis, and induction of cell cycle- and redox-relevant genes ( 21, SOD2), were analysed in LT97 colon adenoma cells. After fermentation, $\mathrm{pH}$ values were reduced ( $\Delta \mathrm{pH}-1.3$, on average) and SCFA concentrations were increased $(\Delta+59 \mathrm{mmol} / \mathrm{L}$, on average) with a shift towards butyrate formation in FS obtained from oat and barley samples compared to the fermentation negative control (FS blank). Ammonia was reduced more effectively in FS obtained from barley ( $\Delta-4.6 \mathrm{mmol} / \mathrm{L}$, on average) than from oat samples ( $\Delta-1.0 \mathrm{mmol} / \mathrm{L}$, on average). Treatment of LT97 cells with FS resulted in a time- and dose-dependent reduction of cell number, an increase in caspase-3 activity (up to 9.0-fold after $24 \mathrm{~h}$, on average) and an induction of $p 21$ (2.1-fold, on average) and SOD2 (2.3-fold, on average) mRNA expression, while no genotoxic effects were observed. In general, the results indicate no concrete effect of the type of cereal or processing stage on fermentation and chemopreventive effects of oat and barley.
\end{abstract}

Keywords Barley $\cdot \beta$-Glucan $\cdot$ Chemoprevention $\cdot$ Colon cancer · Oat

\section{Introduction}

A regular consumption of dietary fibre and whole grains is associated with a reduced risk for colon cancer development. Furthermore, additional health-promoting effects of diets

W. Schlörmann

wiebke.schloermann@uni-jena.de

1 Department of Nutritional Toxicology, Institute of Nutritional Sciences, Friedrich Schiller University Jena, Dornburger Straße 24, 07743 Jena, Germany

2 Competence Cluster for Nutrition and Cardiovascular Health (nutriCARD), Halle-Jena-Leipzig, Jena, Germany

3 Department of Nutritional Biochemistry and Physiology, Institute of Nutritional Sciences, Friedrich Schiller University Jena, Dornburger Straße 25, 07743 Jena, Germany

4 Junior Research Group Nutritional Concepts, Institute of Nutritional Sciences, Friedrich Schiller University Jena, Dornburger Straße 29, 07743 Jena, Germany containing high amounts of dietary fibre and whole grains have been described regarding a risk reduction of cardiovascular disease and type II diabetes [1-4]. In particular, cereals with high amounts of the soluble dietary fibre $\beta$-glucan such as oat and barley have been well studied and approved to positively regulate cholesterol and glucose levels in humans $[5,6]$. It can be assumed that a regular intake of oat and barley may also contribute to colon health or a reduction of colon cancer risk.

On the cellular level, dietary fibre exhibits chemopreventive effects via its metabolites such as short-chain fatty acids (SCFA), particularly butyrate, after fermentation by the microbiota in the colon [7-9]. Therefore, the "blocking" and "suppressing" activities of the well-studied chemopreventive agent butyrate [9] may be at least one mechanism by which oat and barley could contribute to colon cancer prevention. In recent studies, we studied the chemopreventive effects of in vitro digested and fermented oat and barley (betaßbarley) samples in LT97 colon adenoma cells and the impact of 
heat treatment (roasting) on these effects $[10,11]$. We have shown that roasting had no effect on fermentation characteristics such as SCFA formation or on end points of chemoprevention such as induction of apoptosis and growth inhibition. The aim of the present study was to examine the impact of the processing degree of oat and barley (beta ${ }^{\circ}$ barley) on end points of fermentation and chemoprevention. Until now, only a few studies have investigated similar effects of differentially processed oat samples regarding fermentation profiles such as SCFA formation [11-13]. But, there is no sufficient information available on how processing, such as flaking, affects the chemopreventive effects of oat and barley products. The effects of processing on physicochemical properties such as viscosity and the resulting impact on physiological effects such as cholesterol and glycaemic response-lowering capacity have been extensively studied for different types of oat and barley products and in different types of studies [14-20]. For example, flaking involves heat-moisture treatments, which modify the physicochemical characteristics of $\beta$-glucan such as molecular weight and viscosity [21]. The altered structural and physicochemical properties of oat and barley products may also affect digestion and fermentability as well as the resulting chemopreventive metabolites and effects. Therefore, in the present study, differentially processed and commercially available oat and barley samples (kernels, thick flakes, and thin flakes) were directly compared after an in vitro simulated digestion and fermentation regarding fermentation outcomes $(\mathrm{pH}$, concentrations of SCFA, and ammonia). Furthermore, the chemopreventive effects (growth inhibition, apoptosis, gene expression of cell cycle and antioxidant genes) were analysed in LT97 colon adenoma cells as model of early colon carcinogenesis.

\section{Materials and methods}

\section{Oat and barley samples}

Oat kernels as well as thick and thin flakes were obtained from Peter Kölln (Elmshorn, Germany). Barley kernels and the respective thick and thin flakes of a special waxy winter barley variety (beta ${ }^{\circledR}$-barley) with a high $\beta$-glucan content were obtained from Dieckmann Cereals (Rinteln, Germany).

\section{In vitro digestion and fermentation of oat and barley samples}

Oat and barley samples were subjected to an in vitro simulated digestion and batch fermentation as described previously [10]. In brief, $0.5 \mathrm{~g}$ of the samples and the fermentation positive control (Orafti®Synergy1, Beneo, Mannheim, Germany) were reconstituted with $10 \mathrm{ml}$ anaerobic potassium phosphate buffer (0.1 M, pH 7.0). A blank sample without fermentable substrate served as fermentation negative control. Simulation of the digestion was carried out as follows: mouth (17.36 U/sample $\alpha$-amylase, $5 \mathrm{~min}, 37^{\circ} \mathrm{C}$ ), stomach (1.11 mg pepsin in $0.94 \mathrm{~mL} 20 \mathrm{mM} \mathrm{HCl}, \mathrm{pH} 2.0,2 \mathrm{~h}, 37^{\circ} \mathrm{C}$ ) and small intestine $(0.026 \mathrm{~g}$ pancreatin and $0.003 \mathrm{~g}$ oxgall in $5 \mathrm{~mL}$ of $11 \mathrm{mM}$ bicarbonate buffer; $\mathrm{pH} 6.5,6 \mathrm{~h}, 37^{\circ} \mathrm{C}$ in a dialysis membrane, molecular weight cut-off: $500-1000$ Dalton). To simulate the fermentation in the colon, the retentates were mixed with a faeces inoculum mixture obtained from at least three healthy donors. After adjusting the $\mathrm{pH}$ values of each sample to 6.5 , the fermentation was carried out under anaerobic conditions $\left(24 \mathrm{~h}, 37^{\circ} \mathrm{C}\right)$. Subsequently, $\mathrm{pH}$ values were measured and fermentation supernatants (FS) were obtained by centrifugation $(4200 \times \mathrm{g}$ for $30 \mathrm{~min}$, $4200 \times \mathrm{g}$ for $15 \mathrm{~min}$, and $16,000 \times \mathrm{g}$ for $15 \mathrm{~min}, 4^{\circ} \mathrm{C}$ ). FS were stored at $-80{ }^{\circ} \mathrm{C}$ until use. FS were sterile filtered prior to use (Millipore filter, $0.22 \mu \mathrm{m}$ ). The faeces collection was approved by the Ethics Committee of the university hospital of the Friedrich Schiller University Jena. Written informed consent was obtained from all subjects.

\section{Determination of SCFA concentrations}

The concentrations of SCFA in FS of oat and barley samples were measured in duplicate by gas chromatography (GC, GC-17A V3 equipped with an autosampler AOC-5000 and a flame ionisation detector, Shimadzu, Jena, Germany) as described elsewhere [22].

\section{Determination of ammonia concentrations}

Ammonia concentrations in FS obtained from oat and barley samples were measured according to Schlörmann et al. [10] on the basis of the Berthelot reaction [23]. Values were calculated based on the standard dilution series of ammonia chloride.

\section{Culture of LT97 colon adenoma cells}

The human colorectal adenoma cell line LT97 (a kind gift from Professor B. Marian, Institute for Cancer Research, University of Vienna, Austria) was prepared from colon microadenoma of a patient suffering from hereditary familiar polyposis coli [24]. The genetic characteristics of these cells are a mutation in the K-ras oncogene, a deletion of both alleles of the tumour suppressor gene APC and a normally expressed p53 gene [24, 25]. The culture conditions are described in detail by Schlörmann et al. [26]. 


\section{DAPI assay}

The DAPI (4',6-diamidino-2-phenylindol) assay was used to analyse the growth-inhibitory effects of FS obtained from oat and barley samples on LT97 colon adenoma cells as described previously [27]. In brief, LT97 cells were seeded into 96-well plates and grown to a confluence of $20-30 \%$. Cells were treated with $2.5 \%, 5 \%, 10 \%$ and $20 \%$ of FS obtained from oat and barley samples and fermentation controls (blank, Synergy $1{ }^{\circledR}$ ) for $24 \mathrm{~h}, 48 \mathrm{~h}$ and $72 \mathrm{~h}$. Then cells were fixed with methanol $\left(5 \mathrm{~min}, 37^{\circ} \mathrm{C}\right)$ and stained with DAPI $\left(20 \mu \mathrm{M}, 30 \mathrm{~min}, 37^{\circ} \mathrm{C}\right)$. The DNA content as reflection of the cell number was recorded at Ex/ Em of $\lambda=360 / 450 \mathrm{~nm}$ (SpectraFluor Plus, Tecan Germany, Crailsheim, Germany) in six technical replicates per experiment. The blank-corrected results were calculated as relative cell numbers based on the medium control, which was set to $100 \%$. To identify sub-toxic concentrations, $\mathrm{EC}_{25}$ and $\mathrm{EC}_{50}$ values were determined via nonlinear regression/one-phase exponential decay (GraphPad Prism®, GraphPad Software, San Diego, CA, USA) and 2.5\% and 5\% of FS were chosen as concentrations below $\mathrm{EC}_{50}$ for further cell culture experiments.

\section{Caspase assay}

The caspase assay was used to determine the apoptotic effects of FS obtained from oat and barley samples in comparison to FS obtained from fermentation controls (blank, Synergy1 $\left({ }^{\circledR}\right)$. The method has been described in detail previously [28]. Briefly, LT97 cells were seeded into six-well plates and grown to a confluence of 50-60\%. Cells were treated with $2.5 \%$ and $5 \% \mathrm{FS}$ for $24 \mathrm{~h}$ or $48 \mathrm{~h}$ and $4 \mathrm{mM}$ butyrate as positive control. Caspase-3 activity in cell lysates was measured using a caspase-3-specific substrate and inhibitor (Ac-DEVD-AMC, Ac-DEVD-CHO, Enzo Life Science, Lörrach, Germany). Results were calculated relative to the medium control, which was set to 1 .

\section{Comet assay}

The alkaline version of the Comet assay was performed to analyse the genotoxic effects of FS obtained from oat and barley samples in LT97 cells as described earlier [29] with minor modifications. In brief, cells were grown in sixwell plates to a confluence of $50-60 \%$. LT97 cells were treated with $2.5 \%$ and $5 \% \mathrm{FS}$. After treatment for $24 \mathrm{~h}$, cells were harvested and washed with PBS. Cell numbers were adjusted to $0.1 \times 10^{6}$, mixed with $45 \mu 10.7 \%$ low-melting agarose (Biozym, Hessisch Oldendorf, Germany) and spread onto pre-coated $(0.5 \%$ normal melting agarose, Biozym) microscopic slides. The Comet assay procedure and detection of DNA damage (\% TI, tail intensity; means of 100 counted cells) are described by Glei et al. [29].

\section{Analysis of p21 and SOD2 mRNA expression}

The expression of $p 21$ and SOD2 mRNA was measured in treated LT97 cells (5\% FS, $4 \mathrm{mM}$ butyrate, $24 \mathrm{~h}$ ). The isolation, reverse transcription and qPCR procedure and conditions have already been described in detail previously with slight modifications [28]. In brief, cell lysis and RNA isolation were performed using the NucleoSpin ${ }^{\circledR}$ RNA Plus Kit (Machery-Nagel, Düren, Germany) according to the manufacturer`s instructions. RNA integrity was analysed using the Agilent RNA 6000 Nano Kit and the Agilent 2100 Bioanalyzer (Agilent Technologies, Waldbronn, Germany) according to the manufacturer's instructions. All RNA samples revealed a RIN (RNA integrity number) $>9$. Complementary DNA was transcribed from $1.5 \mu \mathrm{g}$ total RNA as described in detail earlier [28]. After dilution of cDNA samples (1:50 in RNAse-free water), qPCR experiments were performed in duplicate in a $10 \mu \mathrm{L}$ reaction mix using the GoTaq ${ }^{\circledR}$ qPCR Master Mix (Promega, Mannheim, Germany) for SOD2, the SsoAdvanced ${ }^{\mathrm{TM}}$ Universal SYBR ${ }^{\circledR}$ Green Supermix (Bio-Rad Laboratories, Munich, Germany) for $p 21$, and the CFX Connect Real-Time PCR Detection System (Bio-Rad Laboratories). The following gene-specific primers $(10 \mathrm{pmol})$ were used for qPCR experiments: $p 21$ forward 5'-CACTGTCTTGTACCCTTGTG-3' and reverse 5'-CTTCCTCTTGGAGAAGAT-3', SOD2 forward 5'-GCC CTGGAACCTCACATCAAC- $3^{\prime}$ and reverse $5^{\prime}$-CAACGC CTCCTGGTACTTCTC-3', $\beta$-actin forward 5'-AGAGCC TCGCCTTTGCCGAT-3' and reverse 5'-CCCACGATG GAGGGGAAGAC-3', GAPDH forward 5'-ACCCACTCC TCCACCTTTGAC- $3^{\prime}$ and reverse 5'-TCCACCACCCTG TTGCTGTAG-3'. The qPCR for SOD2 included the following steps: initial denaturation $\left(2 \mathrm{~min}, 95^{\circ} \mathrm{C}\right), 40$ cycles of denaturation $\left(15 \mathrm{~s}, 94^{\circ} \mathrm{C}\right)$, annealing $\left(15 \mathrm{~s}, 58^{\circ} \mathrm{C}\right)$ and extension $\left(20 \mathrm{~s}, 72^{\circ} \mathrm{C}\right)$, followed by a final extension step $\left(10 \mathrm{~s}, 95^{\circ} \mathrm{C}\right)$. The qPCR for $p 21$ included an initial denaturation $\left(2 \mathrm{~min}, 95^{\circ} \mathrm{C}\right), 40$ cycles of denaturation $\left(30 \mathrm{~s}, 94^{\circ} \mathrm{C}\right)$, annealing $\left(30 \mathrm{~s}, 58^{\circ} \mathrm{C}\right)$ and extension $\left(40 \mathrm{~s}, 72^{\circ} \mathrm{C}\right)$, followed by final extension $\left(10 \mathrm{~min}, 72^{\circ} \mathrm{C}\right)$. Both protocols included a final melting curve analysis. The mRNA expression of $S O D 2$ and $p 21$ was normalised to the geometric mean of two reference genes ( $\beta$-actin, GAPDH) based on the equation of Pfaffl et al. [30]. Statistical analysis was performed with $\log _{2}$-transformed data [31].

\section{Statistical analyses}

Means and standard deviations of at least three independent experiments (unless stated otherwise) were calculated 
and statistical differences were analysed by one-way or twoway ANOVA and Ryan-Einot-Gabriel-Welsh $F$ post hoc test. For comparison of two groups, the unpaired Student's $t$ test was used. Statistical analyses were performed using the SPSS Statistics software for Windows version 25 (IBM Corporation, Armonk, NY, USA).

\section{Results}

\section{pH values and SCFA concentrations}

After fermentation, $\mathrm{pH}$ values of 4.8 were measured in FS obtained from oat and barley samples as well as the fermentation positive control (FS Orafti®Synergy). Thus, these values were considerably lower than the $\mathrm{pH}$ value of the fermentation negative control (FS blank, $\mathrm{pH}=6.1$ ) (Table 1). This reduction of $\mathrm{pH}$ values was associated with an increase in SCFA (acetate, propionate, butyrate). SCFA concentrations measured in the FS obtained from oat and barley samples ranged between 94.9 and $99.5 \mathrm{mmol} / \mathrm{L}$ (Table 1). A similar value was obtained for FS Synergy1 ${ }^{\circledR}$ (96.4 $\mathrm{mmol} / \mathrm{L})$, whereas the blank FS contained the lowest concentrations of SCFA ( $38.6 \mathrm{mmol} / \mathrm{L})$. Furthermore, higher molar ratios of butyrate were determined for FS obtained from oat and barley samples (17.9-21.6\%) and Synergy $1{ }^{\circledR}$ (18.6\%) compared to the blank FS (15.7\%) (Table 1). The shift of molar ratios towards butyrate in FS obtained from oat and barley samples was associated with lower levels of propionate (17.4-19.4\%) and slightly higher levels of acetate (60.1-63.7\%) compared to FS blank (propionate: $24.7 \%$, acetate: $59.6 \%)$. Proportions of propionate $(16.9 \%)$ and acetate $(64.5 \%)$ in FS obtained from Synergy $1 \circledR$ were comparable to that of FS obtained from oat and barley samples.
Interestingly, proportions of propionate in FS obtained from thick and thin oat and barley flakes were slightly higher than in FS obtained from the respective kernels. In contrast, portions of butyrate were slightly lower in FS obtained from thick and thin oat and barley flakes than in FS obtained from the respective kernels.

\section{Ammonia concentrations}

Ammonia concentrations in FS obtained from barley samples (kernels: $11.8 \pm 0.5 \mathrm{mmol} / \mathrm{L}$, thick flakes: $15.2 \pm 0.7 \mathrm{mmol} / \mathrm{L}$, thin flakes: $13.8 \pm 0.5 \mathrm{mmol} / \mathrm{L}, p<0.05)$ were significantly lower than in the blank FS $(18.2 \mathrm{mmol} / \mathrm{L})$ and the FS obtained from the respective oat samples (kernels: $16.4 \pm 0.4 \mathrm{mmol} / \mathrm{L}$, thick flakes: $18.1 \pm 0.5 \mathrm{mmol} / \mathrm{L}$, thin flakes: $17.1 \pm 0.2 \mathrm{mmol} / \mathrm{L}$ ) (Table 1). Here, a significant reduction of ammonia, in comparison to the blank FS, was only observed for oat kernels $(p<0.05)$. The strongest reduction of ammonia was measured in FS obtained from Synergy $1 \circledR(5.7 \pm 0.8 \mathrm{mmol} / \mathrm{L})$.

\section{Growth inhibition}

Treatment of LT97 cells with FS obtained from oat and barley samples resulted in a time- and dose-dependent inhibition of cell growth (Fig. 1). After treatment for $24 \mathrm{~h}$ with $2.5-20 \%$ FS obtained from oat and barley samples, mean cell numbers were reduced to $63.4-26.2 \%$ compared to the medium control, which was set as $100 \%$ (Fig. 1A). This reduction was comparable to that observed for $2.5-20 \%$ of the fermentation positive control (FS Synergy $\left.1{ }^{\circledR}\right)$, which caused a reduction to $67.4-21.3 \%$. Treatment with $2.5-20 \%$ of the fermentation negative control (FS blank) led to a reduction to $74.4-9.8 \%$. The most

Table $1 \mathrm{pH}$ values, SCFA concentration, molar ratio of main SCFA, and ammonia concentrations in FS of oat and barley samples

\begin{tabular}{|c|c|c|c|c|c|c|c|c|}
\hline & \multicolumn{2}{|l|}{ FS controls } & \multicolumn{3}{|c|}{ FS oat samples } & \multicolumn{3}{|c|}{ FS barley samples } \\
\hline & Blank & Synergy $1 \circledR$ & Kernels & Thick flakes & Thin flakes & Kernels & Thick flakes & Thin flakes \\
\hline $\mathrm{pH}$ & 6.1 & 4.8 & 4.8 & 4.8 & 4.8 & 4.8 & 4.8 & 4.8 \\
\hline Acetate $[\mathrm{mmol} / \mathrm{L}]$ & 23.0 & 62.2 & 61.8 & 62.9 & 63.2 & 57.1 & 61.1 & 59.9 \\
\hline Propionate $[\mathrm{mmol} / \mathrm{L}]$ & 9.5 & 16.3 & 16.9 & 18.1 & 18.5 & 17.3 & 18.7 & 18.8 \\
\hline Butyrate $[\mathrm{mmol} / \mathrm{L}]$ & 6.1 & 17.9 & 18.3 & 18.2 & 17.8 & 20.5 & 18.6 & 18.3 \\
\hline$\sum$ SCFA $[\mathrm{mmol} / \mathrm{L}]$ & 38.6 & 96.4 & 96.9 & 99.2 & 99.5 & 94.9 & 98.4 & 97.0 \\
\hline Molar ratio acetate [\%] & 59.6 & 64.5 & 63.7 & 63.4 & 63.5 & 60.1 & 62.1 & 61.8 \\
\hline Molar ratio propionate [\%] & 24.7 & 16.9 & 17.4 & 18.3 & 18.6 & 18.3 & 19.0 & 19.4 \\
\hline Molar ratio butyrate $[\%]$ & 15.7 & 18.6 & 18.9 & 18.3 & 17.9 & 21.6 & 18.9 & 18.8 \\
\hline Ammonia $[\mathrm{mmol} / \mathrm{L}]^{\text {(a) }}$ & $18.2 \pm 0.6^{\mathrm{a}}$ & $5.7 \pm 0.8^{f}$ & $16.4 \pm 0.4^{\mathrm{c}, \mathrm{b}}$ & $18.1 \pm 0.5^{\mathrm{a}}$ & $17.1 \pm 0.2^{\mathrm{a}, \mathrm{b}}$ & $11.8 \pm 0.5^{\mathrm{e}}$ & $15.2 \pm 0.7^{\mathrm{c}}$ & $13.8 \pm 0.5^{\mathrm{d}}$ \\
\hline
\end{tabular}

Results are presented as means of two or as means \pm SD of three ${ }^{(a)}$ independent measurements. Significant differences between ammonia concentrations measured in blank, Synergy $1{ }^{\circledR}$ and FS obtained from oat and barley samples $(\mathrm{a}, \mathrm{b}, \mathrm{c}, \mathrm{d}, \mathrm{e}, \mathrm{f} p<0.05$, different letters represent statistically different results) were obtained by one-way ANOVA and $F$ test according to Ryan-Einot-Gabriel-Welsh

FS fermentation supernatant, SCFA short-chain fatty acids 
Fig. 1 Relative cell number [\%] calculated on the basis of the medium control (dashed line), which was set $100 \%$ (mean $+\mathrm{SD}, n=3)$. LT97 cells were treated with different concentrations $(2.5-20 \%)$ of fermentation supernatants (FS) obtained from oat and barley samples as well as fermentation controls (FS blank, FS Syn$\operatorname{ergy} 1 \circledR)$ for A $24 \mathrm{~h}, \mathbf{B} 48 \mathrm{~h}$, and C 72 h. Significant differences between cells treated with FS blank and cells treated with FS of Synergy $1{ }^{\circledR}$ and oat as well as barley samples $(\# p<0.05)$ and significant differences between cells treated with different concentrations of FS (a, b, c, d $p<0.05$, different letters represent significantly different results) were obtained by oneway ANOVA and $F$ test according to Ryan-Einot-GabrielWelsh
A

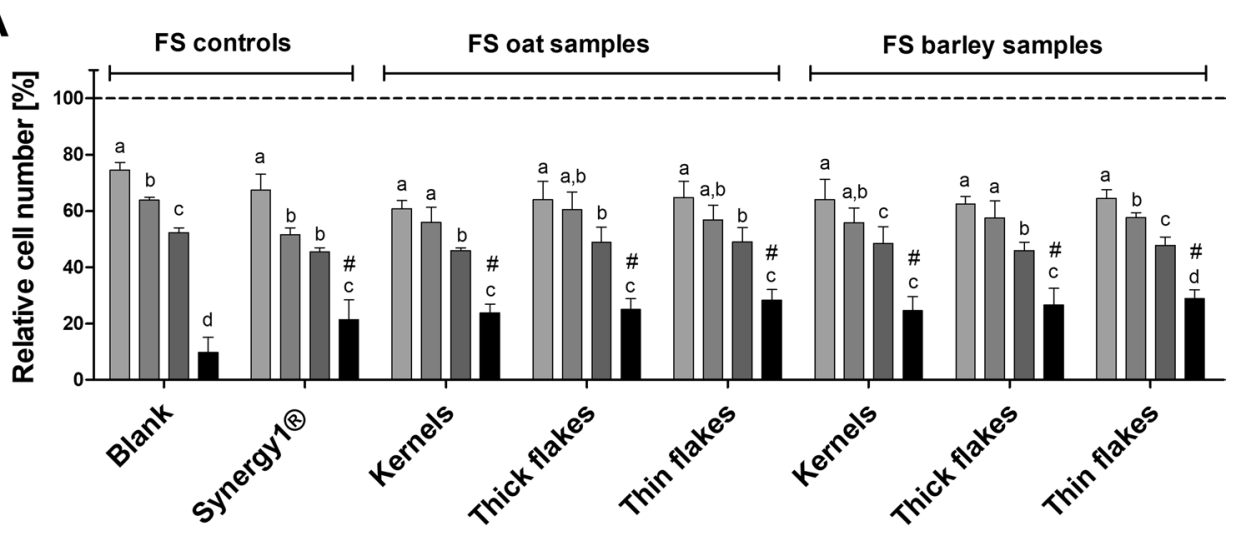

B

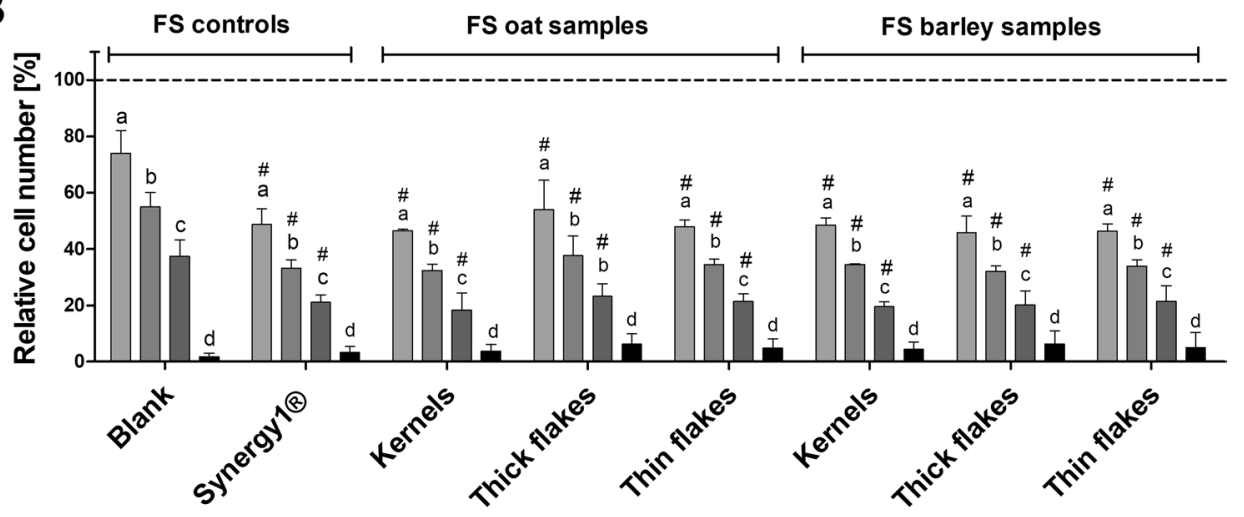

C

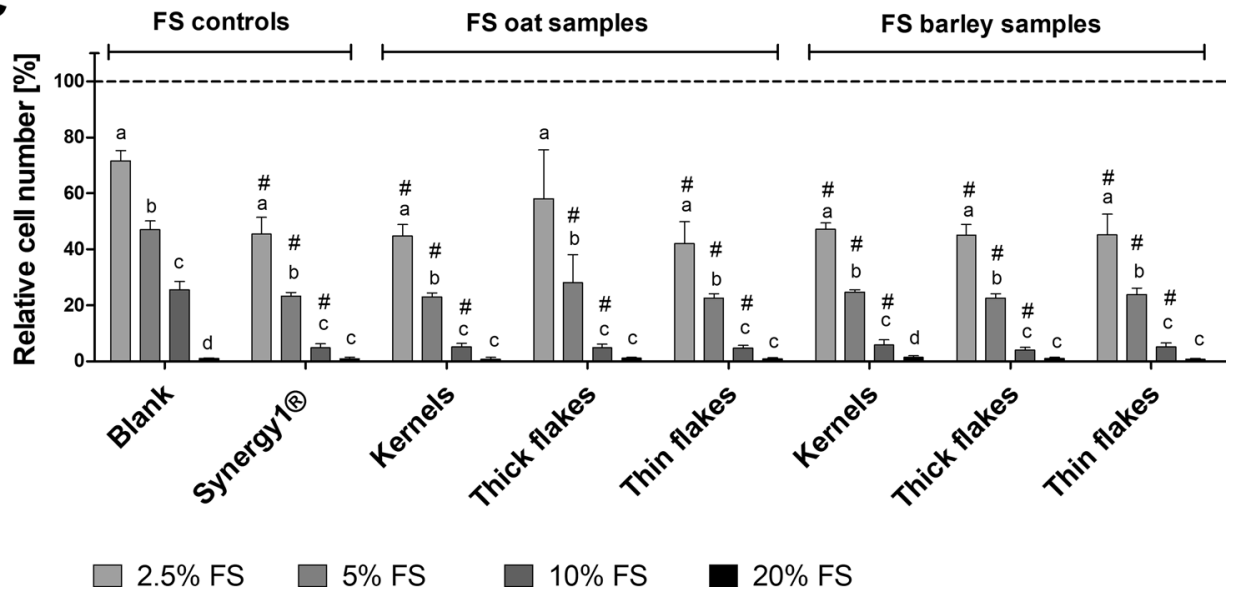

intense growth inhibition was observed after $48 \mathrm{~h}$ (down to $48.2-5.1 \%$ on average, Fig. 1B) and $72 \mathrm{~h}$ (down to $47.0-$ $1.0 \%$ on average, Fig. 1C) of treatment with $2.5-20 \%$ FS obtained from oat and barley samples. Here, $2.5 \%, 5 \%$ and $10 \%$ of fermented oat and barley samples as well as FS of Synergy $1{ }^{\circledR}$ significantly reduced LT97 cells numbers in comparison to the FS blank $(p<0.05)$. No distinct differences were observed between treatments with oat or barley samples or different processing degrees (kernels or flakes). Based on this results, 5\% FS was chosen as highest "sub-toxic" concentrations for further cell culture experiments.

\section{Genotoxic effects}

To exclude genotoxic effects of FS, LT97 cells were treated with 5\% FS obtained from oat and barley samples as well as fermentation controls (blank, Synergy1®) and subjected to Comet assay analysis. With a mean tail intensity (TI) of $39.6 \%$, the positive control $\mathrm{H}_{2} \mathrm{O}_{2}(75 \mu \mathrm{M})$ induced significant 


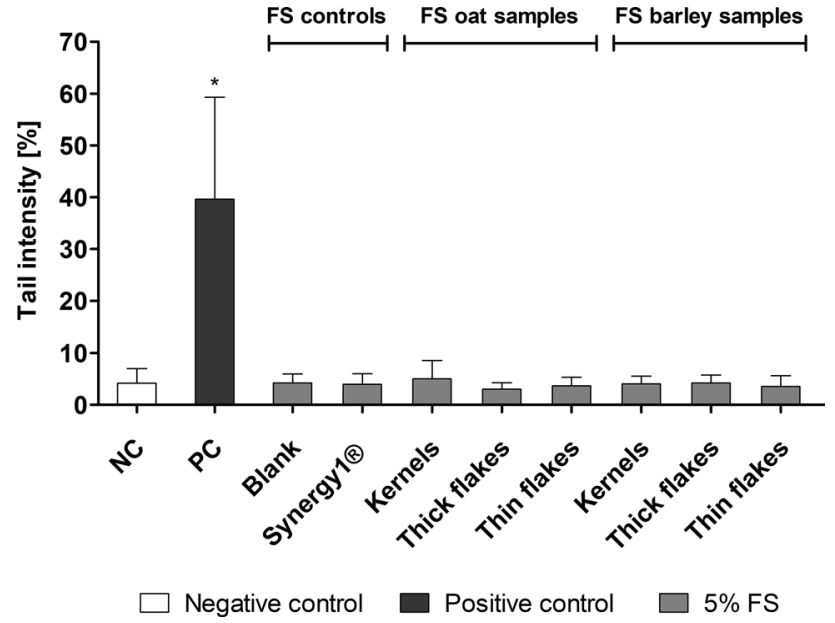

Fig. 2 Tail intensity [\%] after treatment of LT97 cells with 5\% fermentation supernatants (FS) obtained from oat and barley samples as well as fermentation controls (FS blank, FS Synergy $1{ }^{\circledR}$ ) for $24 \mathrm{~h}$ (mean $+\mathrm{SD}, n=4)$. Significant differences between cells treated with medium (NC) and cells treated with FS obtained from oat and barley samples as well as with the positive control ( $\mathrm{PC}, 75 \mu \mathrm{M} \mathrm{H}_{2} \mathrm{O}_{2}$ ) were tested with one-way ANOVA and $F$ test according to Ryan-EinotGabriel-Welsh ( $\left.{ }^{*} p<0.05\right)$

DNA damage compared to the medium control (negative control, $\mathrm{TI}=4.2 \%, p<0.05$ ). Tail intensities induced by FS obtained from oat and barley samples as well as FS blank and Synergy $1 \circledR$ were in the range of 3.5-4.0\% (Fig. 2). Thus, these TIs were comparable to that induced by the medium control. Differences between oat and barley samples were not found.

\section{Induction of apoptosis}

To analyse apoptotic effects of oat and barley, caspase-3 activity was measured in LT97 cells after treatment with 5\% FS obtained from oat and barley samples and fermentation controls (FS blank, FS Synergy1®). The positive control butyrate $(4 \mathrm{mM})$ significantly increased caspase-3 activity in comparison to the medium (set as 1 ) after $24 \mathrm{~h}$ (13.2-fold, $p<0.05)$ and $48 \mathrm{~h}(11.1$-fold, $p<0.05)$ treatment (Fig. 3A, B). The FS obtained from Synergy $1{ }^{\circledR}$ led to significantly higher caspase-3 activity levels after $24 \mathrm{~h}$ (10.2fold, $p<0.05)$ and $48 \mathrm{~h}(8.0$-fold, $p<0.05)$ than the FS of the blank, which had no significant increasing effect ( $24 \mathrm{~h}$ : 2.2-fold, 48 h: 1.6-fold). Similar significant increases were induced by FS obtained from oat and barley samples. After $24 \mathrm{~h}$, caspase- 3 activity was enhanced 9.2-fold $(p<0.05)$, 8.8 -fold $(p<0.05)$ and 6.6 -fold $(p<0.05)$ by FS obtained from oat kernels and thick as well as thin oat flakes, respectively. Slightly higher increases were measured after treatment with FS obtained from barley kernels (11.7-fold), thick

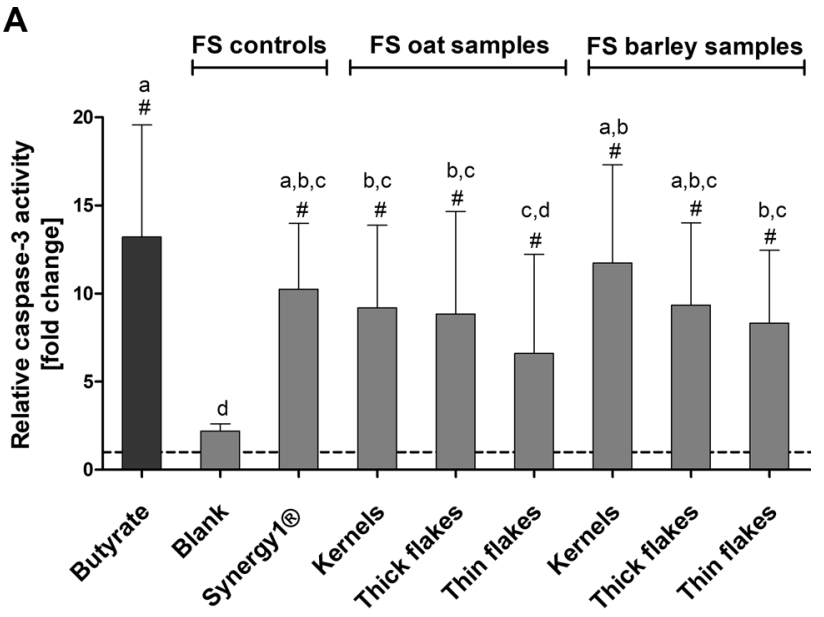

B
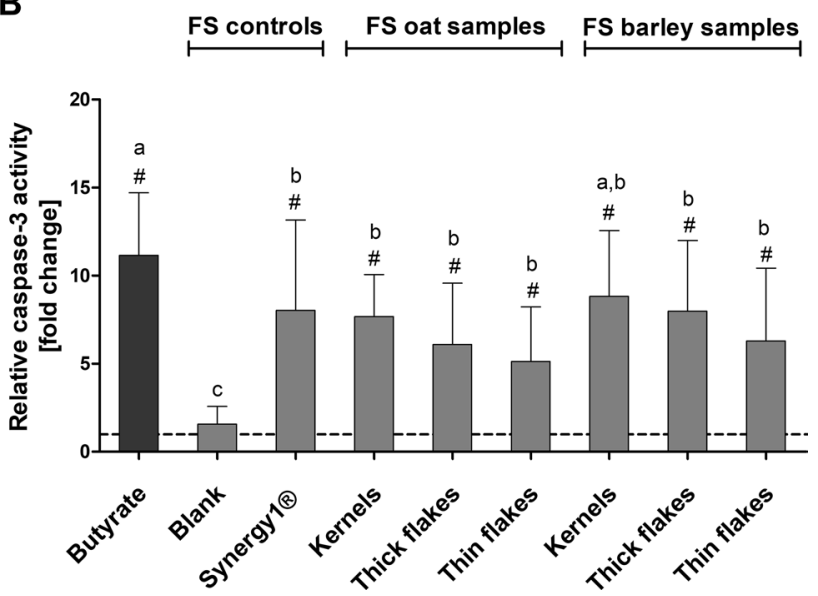

Fig. 3 Relative activity of caspase- 3 presented as fold changes on the basis of a medium control, which was set 1 (dashed line). LT97 cells were treated with $5 \%$ fermentation supernatants (FS) obtained from oat and barley samples and controls ( $4 \mathrm{mM}$ butyrate, FS blank, FS Synergy 1®) for A $24 \mathrm{~h}$ and B $48 \mathrm{~h}($ mean $+\mathrm{SD}, n=5)$. Significant differences compared to the medium-treated cells $\left({ }^{\#} p<0.05\right)$ and significant differences between FS- or butyrate-treated cells ( $(\mathrm{a}, \mathrm{b}$, ${ }^{c,}{ }_{p} p<0.05$, different letters represent significantly different results) were obtained by two-way ANOVA and $F$ test according to RyanEinot-Gabriel-Welsh

barley flakes (9.3-fold) and thin barley flakes (8.3-fold) (Fig. 3A). After $48 \mathrm{~h}$, the significant increase of caspase-3 activities ranged between 5.1- and 7.7-fold $(p<0.05)$ after treatment with FS obtained from oat samples and between 6.3- and 8.8-fold $(p<0.05)$ after incubation with FS obtained from barley samples (Fig. 3B).

\section{Modulation of mRNA expression of p21 and SOD2}

Treatment of LT97 cells with FS obtained from oat and barley samples resulted in significantly higher levels of $p 21$ mRNA in the range of 1.7 - to 2.5 -fold $(p<0.05)$ (Fig. 4A) 

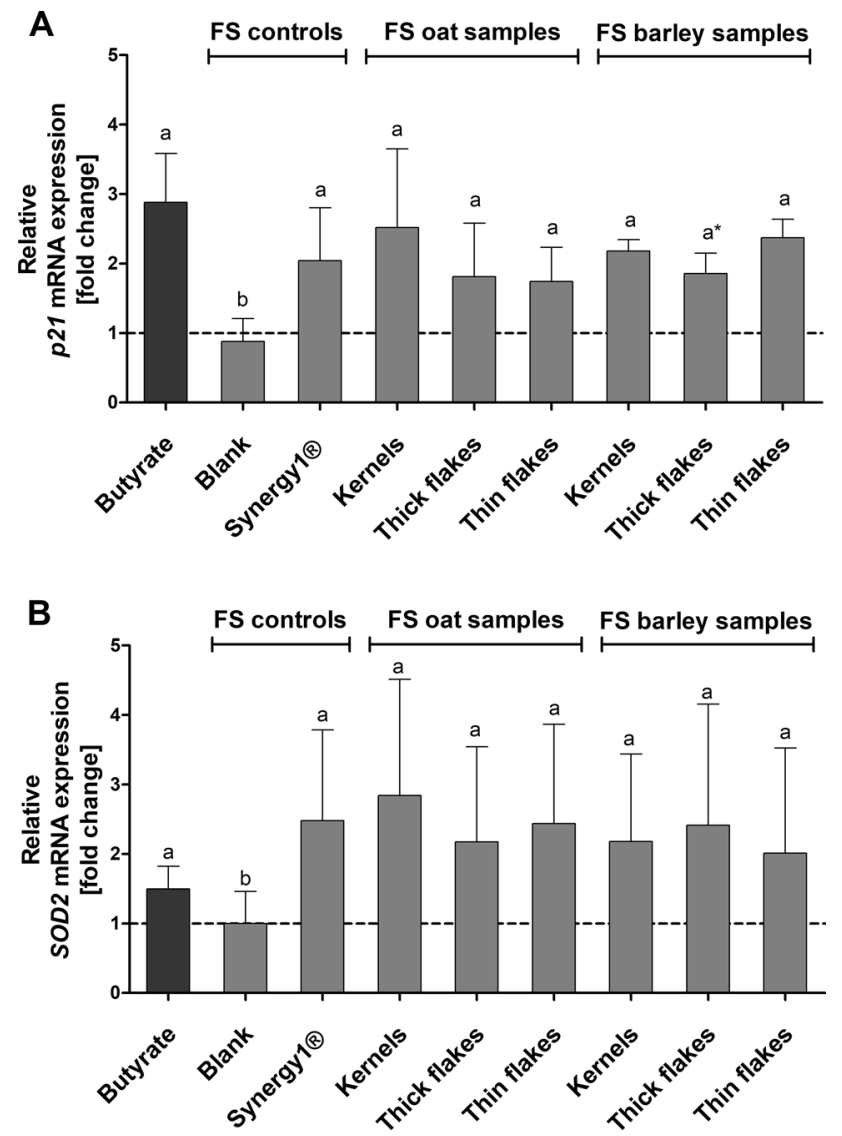

Fig. 4 Relative expression of A p21 and B SOD2 mRNA presented as fold changes on the basis of a medium control, which was set 1 (dashed line). LT97 cells were treated with 5\% fermentation supernatants (FS) obtained from oat and barley samples as well as controls (4 mM butyrate, FS blank, FS Synergy $1 \circledR)$ for $24 \mathrm{~h}($ mean + SD, $n=3, * n=2$ ). Significant differences between cells treated with the particular FS obtained from oat and barley samples as well as with butyrate $\left({ }^{\mathrm{a},} \mathrm{b} p<0.05\right.$, different letters represent significantly different results) were obtained from $\log _{2}$-transformed data by two-way ANOVA and $F$ test according to Ryan-Einot-Gabriel-Welsh

than incubation with FS blank (0.9-fold). Similarly, FS obtained from Synergy $1 \circledast$ also induced a significant increase of $p 21 \mathrm{mRNA}$ levels (2.0-fold, $p<0.05$ ). This increase of p21 mRNA expression by FS obtained from oat and barley samples was comparable to that induced by the positive control butyrate (2.9-fold, $p<0.05$ ).

SOD2 mRNA expression was significantly higher in LT97 cells after treatment with FS obtained from oat and barley samples (2.0- to 2.8-fold, $p<0.05$ ) as well as Synergy $1{ }^{\circledR}$ (2.5-fold, $p<0.05)$ than after incubation with FS blank (1.0fold). Butyrate increased SOD2 mRNA levels 1.5-fold. In general, no significant differences were observed between treatments with oat or barley samples or different processing degrees.

\section{Discussion}

Several studies already examined the impact of processing (e.g. flaking, extrusion) on oat and barley as well as on oator barley-derived $\beta$-glucans regarding their physiochemical properties, such as viscosity, and health-promoting properties, particularly their cholesterol and glucose regulating potential [14, 16, 18-21, 32, 33]. Processing such as flaking involves heat-moisture treatments, which modify the physicochemical characteristics of $\beta$-glucan and other compounds (e.g. starch) [20, 21, 32], which might affect the digestibility and fermentability of oat and barley products. But until now, studies investigating the impact of processing such as flaking on the fermentation profile [12, 13] and resulting consequences for their chemopreventive potential are rare. In recent studies, we investigated the impact of heat treatment (roasting) on fermentation characteristics and chemopreventive effects of oat and barley flakes $[10,11]$ in separate fermentation experiments. Furthermore, we found higher viscosities for oat and barley flakes than for the respective kernels [34, 35]. Therefore, the focus of the present study was to examine the end points of fermentation and chemoprevention in oat and barley samples with different degrees of processing (kernels, thick flakes, and thin flakes).

The results obtained after fermentation of oat and barley samples revealed no impact of the processing degree on the fermentation profile. Overall, $\mathrm{pH}$ values were reduced, SCFA concentrations were increased and ammonia concentrations were reduced, particularly after fermentation of barley samples. Here, fermentation of kernels led to significantly lower ammonia levels than the fermentation of flakes, which might indicate a better accessibility and proteolytic fermentability in flakes. Furthermore, the proportions of butyrate were increased in FS of the cereals. In general, these results are in line with the results obtained in former studies $[10,11]$, and concentrations of SCFA and ammonia nearly reflect the in vivo situation of $70-140 \mathrm{mM}$ for the proximal colon [36] and $30 \mathrm{mM}$ for human faeces [37], respectively. In contrast to our study, other studies revealed a more propionate-rich fermentation profile after fermentation of oat products $[12,13,38]$ or $\beta$-glucan derived from oat and barley [39]. These higher propionate concentrations might be the result of using different food matrices such oat bran [38] and isolated glucans [39]. For example, fermentation of oat flours results in a fermentation profile, which is also rich in butyrate [40]. Furthermore, a pH-controlled fermentation procedure such as that performed by Connolly et al. [12] and Hughes et al. [39] results in a propionate-rich fermentation profile, while acidification during fermentation, as reflected by our results, favours butyrate formation [41]. In the present study, marginal differences were observed in the proportions 
of butyrate and propionate in kernels and flakes, particularly thin flakes. Whether this small increase of propionate with a simultaneous decrease of butyrate in thin flakes compared to kernels might indicate an effect of the processing degree has to be investigated in more detail in further experiments. Connolly et al. for example found nearly threefold higher concentrations of butyrate after fermentation of thick compared to thin oat flakes [12].

Since butyrate is a well-known chemopreventive agent $[7,9]$ and high ammonia concentrations resulting from proteolytic fermentation are associated with adverse effects regarding colon health $[37,42]$, the increase of butyrate and decrease of ammonia might be associated with a reduced risk for colon cancer development. Butyrate might also be responsible for the inhibitory effects of FS obtained from oat and barley samples on LT97 colon adenoma cell growth via induction of apoptosis as reflected by increased caspase-3 activity levels. Similar effects on colon adenoma or carcinoma cells by FS obtained from different dietary fibre sources, such as wheat aleurone [43], bread [27] and nuts [28] or by butyrate alone [44, 45], have been reported earlier and may be mainly mediated by the function of butyrate as histone deacetylase inhibitor [7-9]. In a recent study, we demonstrated growth-inhibitory and apoptotic effects of FS obtained from differentially roasted oat and barley flakes $[10,11]$. Here, the heat treatment had no distinct impact on growth inhibition and caspase- 3 activity. Similarly, in the present study no significant differences were detected between growth-inhibitory and apoptotic effects of FS obtained from kernels and thick and thin flakes, though there is a marginal decrease in the induction of capsase- 3 activity from kernels to thin flakes (average $\Delta$ fold-change: $2.5-3.4$ ). This may be explained by the above-mentioned small differences in butyrate concentrations. Though butyrate may be mainly responsible for the observed effects, the FS obtained from oat and barley kernels and flakes represent complex mixtures of different metabolites, which might contribute to the induction of growth inhibition and apoptosis. For example, similar effects have been described for propionate, although to a lesser extent $[27,44,46]$. Furthermore, secondary bile acids such as deoxycholic acid (DCA) resulting from the faeces matrix might be responsible particularly for the growth-inhibitory effects of the fermentation blank control. Several studies indicate that secondary bile acids such as DCA reduce the growth of colon adenoma or carcinoma cells [47-49]. The blank FS might contain higher concentrations of DCA than FS obtained from oat and barley samples as shown earlier in fermentation experiments with other dietary fibre sources [50]. Furthermore, Naumann et al. [51] demonstrated that dietary fibre-enriched food interacts with bile acids and that particularly oat and barley have highly adsorptive properties for bile acids such as DCA. In contrast to the above-mentioned growth-inhibiting effects of bile acids on colon cancer cells, continuously high concentrations of secondary bile acids are associated with an increased colon cancer risk [47, 52]. Therefore, a reduction of DCA by dietary fibre may exhibit positive effects regarding colon health. Nevertheless, synergistic effects on cell growth and apoptosis by other metabolites resulting from fermentation of oat and barley samples cannot be excluded. Furthermore, the elevated levels of $p 21$ mRNA expression induced in LT97 cells by FS obtained from oat and barley samples might indicate that an initiation of cell cycle arrest may contribute to the growth-inhibitory effects. A genotoxic contribution to growth inhibition and apoptosis can be excluded since tail intensities were not increased by FS obtained from oat and barley samples, at least for the time points and concentrations used in the present study.

An increase of $p 21$ mRNA levels in LT97 cells after treatment with FS obtained from other dietary fibre sources has already been shown [28, 53]. Again, this gene-modulatory effect of oat and barley FS in LT97 cells may be mediated at least partly by butyrate via its function as histone deacetylase inhibitor. The modulation of cell cycle-relevant genes by butyrate in colon adenoma $[45,53]$ or carcinoma cells [8, 53-55] has been shown in several studies. Furthermore, the induction of the antioxidant-relevant gene SOD2 by FS obtained from oat and barley samples may also be partly attributed to butyrate as shown in earlier studies [28]. The modulation of gene expression by FS obtained from oat and barley samples was unaffected by the degree of processing.

Taken together, the results indicate that the fermented oat and barley samples exhibit chemopreventive effects via "suppressing" and "blocking" activities, which are at least partly mediated by butyrate as fermentation product. Nevertheless, FS obtained from oat and barley samples represent complex mixtures of metabolites and other compounds or mechanisms might contribute to the observed effects. Importantly, only marginal differences were observed in the fermentation profile of kernels, thick and thin flakes and the chemopreventive effects of fermented oat and barley samples were largely unaffected by the degree of processing or the type of cereal.

Acknowledgements This IGF project (AiF 19351 BR) of the FEI (Research Association of the German Food Industry) was supported via $\mathrm{AiF}$ (German Federation of Industrial Research Associations) within the programme for promoting the Industrial Collective Research (IGF) of the German Ministry of Economic Affairs and Energy (BMWi), based on a resolution of the German Parliament. We would like to thank Dieckmann Cereals GmbH (Rinteln, Germany) for allocation of barley products and we thank Peter Kölln GmbH \& Co. KGaA (Elmshorn, Germany) for allocation of oat products. Furthermore, we would like to express our gratitude to Sandra Hebestreit from the Department of Nutritional Toxicology for her excellent technical assistance. We also thank Carsten Rohrer from the Department of Nutritional Biochemistry and Physiology for performing SCFA analysis. 
Author contributions WS: conceptualisation, validation, formal analysis, investigation, data curation, writing - original draft, visualisation, supervision, project administration, funding acquisition. FK: formal analysis, investigation, data curation, visualisation. SZ: formal analysis, investigation, data curation, visualisation. $\mathrm{CD}$ : funding acquisition, writing - review and editing. SL: funding acquisition, writing - review and editing. MG: conceptualisation, funding acquisition, supervision, project administration, funding acquisition, writing-original draft, writing — review and editing. All authors read and approved the manuscript.

Funding Open Access funding enabled and organized by Projekt DEAL.

\section{Compliance with ethical standards}

Conflict of interest The authors declare that they have no conflict of interest.

Compliance with ethics requirements All procedures performed in studies involving human participants have been approved by the Ethics Committee of the university hospital of the Friedrich Schiller University Jena. Written informed consent was obtained from all subjects.

Open Access This article is licensed under a Creative Commons Attribution 4.0 International License, which permits use, sharing, adaptation, distribution and reproduction in any medium or format, as long as you give appropriate credit to the original author(s) and the source, provide a link to the Creative Commons licence, and indicate if changes were made. The images or other third party material in this article are included in the article's Creative Commons licence, unless indicated otherwise in a credit line to the material. If material is not included in the article's Creative Commons licence and your intended use is not permitted by statutory regulation or exceeds the permitted use, you will need to obtain permission directly from the copyright holder. To view a copy of this licence, visit http://creativecommons.org/licenses/by/4.0/.

\section{References}

1. Aune D, Chan DSM, Lau R, Vieira R, Greenwood DC, Kampman $\mathrm{E}$, et al (2011) Dietary fibre, whole grains, and risk of colorectal cancer: systematic review and dose-response meta-analysis of prospective studies. Br Med J 343

2. Malcomson FC (2018) Mechanisms underlying the effects of nutrition, adiposity and physical activity on colorectal cancer risk. Nutr Bull 43:400-415

3. Tieri M, Ghelfi F, Vitale M, Vetrani C, Marventano S, Lafranconi A et al (2020) Whole grain consumption and human health: an umbrella review of observational studies. Int J Food Sci Nutr 71:668-677

4. O'Keefe SJ (2019) The association between dietary fibre deficiency and high-income lifestyle-associated diseases: Burkitt's hypothesis revisited. Lancet Gastroenterol Hepatol 4:984-996

5. EFSA (2011) Scientific Opinion on the substantiation of health claims related to beta-glucans from oats and barley and maintenance of normal blood LDL-cholesterol concentrations (ID 1236, 1299), increase in satiety leading to a reduction in energy intake (ID 851,852 ), reduction of post-prandial glycaemic responses (ID 821, 824), and "digestive function" (ID 850) pursuant to Article 13(1) of Regulation (EC) No 1924/2006. EFSA J 9:2207
6. Schlörmann W, Glei M (2017) Potential health benefits of betaglucan from barley und oat. Ernahrungs Umschau 64:M555-M559

7. Hamer HM, Jonkers D, Venema K, Vanhoutvin S, Troost FJ, Brummer RJ (2008) Review article: the role of butyrate on colonic function. Aliment Pharmacol Ther 27:104-119

8. Hinnebusch BF, Meng S, Wu JT, Archer SY, Hodin RA (2002) The effects of short-chain fatty acids on human colon cancer cell phenotype are associated with histone hyperacetylation. J Nutr 132:1012-1017

9. Scharlau D, Borowicki A, Habermann N, Hofmann T, Klenow S, Miene C et al (2009) Mechanisms of primary cancer prevention by butyrate and other products formed during gut flora-mediated fermentation of dietary fibre. Mutat Res 682:39-53

10. Schlörmann W, Atanasov J, Lorkowski S, Dawczynski C, Glei M (2020) Study on chemopreventive effects of raw and roasted $\beta$-glucan-rich waxy winter barley using an in vitro human colon digestion model. Food Funct 11:2626-2638

11. Glei M, Zetzmann S, Lorkowski S, Dawczynski C, Schlörmann W (2020) Chemopreventive effects of raw and roasted oat flakes after in vitro fermentation with human faecal microbiota. Int $\mathbf{J}$ Food Sci Nutr 1-13

12. Connolly ML, Lovegrove JA, Tuohy KM (2010) In vitro evaluation of the microbiota modulation abilities of different sized whole oat grain flakes. Anaerobe 16:483-488

13. Van den Abbeele P, Kamil A, Fleige L, Chung Y, De Chavez P, Marzorati M (2018) Different oat ingredients stimulate specific microbial metabolites in the gut microbiome of three human individuals in vitro. ACS Omega 3:12446-12456

14. Granfeldt Y, Eliasson AC, Bjorck I (2000) An examination of the possibility of lowering the glycemic index of oat and barley flakes by minimal processing. J Nutr 130:2207-2214

15. Grundy MML, Quint J, Rieder A, Ballance S, Dreiss CA, Cross KL et al (2017) The impact of oat structure and beta-glucan on in vitro lipid digestion. J Funct Foods 38:378-388

16. Henrion M, Francey C, Le KA, Lamothe L (2019) Cereal B-glucans: the impact of processing and how it affects physiological responses. Nutrients 11:1729

17. Makela N, Brinck O, Sontag-Strohm T (2020) Viscosity of betaglucan from oat products at the intestinal phase of the gastrointestinal model. Food Hydrocolloid 100:105422

18. Regand A, Tosh SM, Wolever TM, Wood PJ (2009) Physicochemical properties of beta-glucan in differently processed oat foods influence glycemic response. J Agric Food Chem 57:8831-8838

19. Tosh SM (2013) Review of human studies investigating the postprandial blood-glucose lowering ability of oat and barley food products. Eur J Clin Nutr 67:310-317

20. Tosh SM, Chu YF (2015) Systematic review of the effect of processing of whole-grain oat cereals on glycaemic response. Br J Nutr 114:1256-1262

21. Ames N, Storsley J, Tosh S (2015) Effects of processing on physicochemical properties and efficacy of beta-glucan from oat and barley. Cereal Food World 60:4-8

22. Klein A, Friedrich U, Vogelsang H, Jahreis G (2008) Lactobacillus acidophilus 74-2 and Bifidobacterium animalis subsp lactis DGCC 420 modulate unspecific cellular immune response in healthy adults. Eur J Clin Nutr 62:584-593

23. Chaney AL, Marbach EP (1962) Modified reagents for determination of urea and ammonia. Clin Chem 8:130-132

24. Richter M, Jurek D, Wrba F, Kaserer K, Wurzer G, KarnerHanusch J et al (2002) Cells obtained from colorectal microadenomas mirror early premalignant growth patterns in vitro. Eur J Cancer 38:1937-1945

25. Veeriah S, Hofmann T, Glei M, Dietrich H, Will F, Schreier P et al (2007) Apple polyphenols and products formed in the gut differently inhibit survival of human cell lines derived from colon 
adenoma (LT97) and carcinoma (HT29). J Agric Food Chem 55:2892-2900

26. Schlörmann W, Lamberty J, Ludwig D, Lorkowski S, Glei M (2017) In vitro-fermented raw and roasted walnuts induce expression of CAT and GSTT2 genes, growth inhibition, and apoptosis in LT97 colon adenoma cells. Nutr Res 47:72-80

27. Schlörmann W, Hiller B, Jahns F, Zoger R, Hennemeier I, Wilhelm A et al (2012) Chemopreventive effects of in vitro digested and fermented bread in human colon cells. Eur J Nutr 51:827-839

28. Schlörmann W, Lamberty J, Lorkowski S, Ludwig D, Mothes $\mathrm{H}$, Saupe C et al (2017) Chemopreventive potential of in vitro fermented nuts in LT97 colon adenoma and primary epithelial colon cells. Mol Carcinog 56:1461-1471

29. Glei M, Fischer S, Lamberty J, Ludwig D, Lorkowski S, Schlörmann W (2018) Chemopreventive potential of in vitro fermented raw and roasted hazelnuts in LT97 colon adenoma cells. Anticancer Res 38:83-93

30. Pfaffl MW, Horgan GW, Dempfle L (2002) Relative expression software tool (REST) for group-wise comparison and statistical analysis of relative expression results in real-time PCR. Nucleic Acids Res 30:36

31. Rieu I, Powers SJ (2009) Real-time quantitative RT-PCR: design, calculations, and statistics. Plant Cell 21:1031-1033

32. Regand A, Chowdhury Z, Tosh SM, Wolever TMS, Wood P (2011) The molecular weight, solubility and viscosity of oat beta-glucan affect human glycemic response by modifying starch digestibility. Food Chem 129:297-304

33. Wolever TMS, Tosh SM, Gibbs AL, Brand-Miller J, Duncan AM, Hart V et al (2010) Physicochemical properties of oat beta-glucan influence its ability to reduce serum LDL cholesterol in humans: a randomized clinical trial. Am J Clin Nutr 92:723-732

34. Schlörmann W, Zetzmann S, Wiege B, Haase NU, Greiling A, Lorkowski $S$ et al (2019) Impact of different roasting conditions on chemical composition, sensory quality and physicochemical properties of waxy-barley products. Food Funct 10:5436-5445

35. Schlörmann W, Zetzmann S, Wiege B, Haase NU, Greiling A, Lorkowski $S$ et al (2020) Impact of different roasting conditions on sensory properties and health-related compounds of oat products. Food Chem 307:125548

36. Topping DL, Clifton PM (2001) Short-chain fatty acids and human colonic function: roles of resistant starch and nonstarch polysaccharides. Physiol Rev 81:1031-1064

37. Hughes R, Magee EA, Bingham S (2000) Protein degradation in the large intestine: relevance to colorectal cancer. Curr Issues Intest Microbiol 1:51-58

38. Nordlund E, Aura AM, Mattila I, Kosso T, Rouau X, Poutanen K (2012) Formation of phenolic microbial metabolites and shortchain fatty acids from rye, wheat, and oat bran and their fractions in the metabolical in vitro colon model. J Agric Food Chem 60:8134-8145

39. Hughes SA, Shewry PR, Gibson GR, McCleary BV, Rastall RA (2008) In vitro fermentation of oat and barley derived beta-glucans by human faecal microbiota. Fems Microbiol Ecol 64:482-493

40. Kim HJ, White PJ (2009) In vitro fermentation of oat flours from typical and high beta-glucan oat lines. J Agric Food Chem 57:7529-7536

41. Louis P, Flint HJ (2017) Formation of propionate and butyrate by the human colonic microbiota. Environ Microbiol 19:29-41
42. Windey K, De Preter V, Verbeke K (2012) Relevance of protein fermentation to gut health. Mol Nutr Food Res 56:184-196

43. Borowicki A, Stein K, Scharlau D, Scheu K, Brenner-Weiss G, Obst U et al (2010) Fermented wheat aleurone inhibits growth and induces apoptosis in human HT29 colon adenocarcinoma cells. Br J Nutr 103:360-369

44. Kautenburger T, Beyer-Sehlmeyer G, Festag G, Haag N, Kuhler S, Kuchler A et al (2005) The gut fermentation product butyrate, a chemopreventive agent, suppresses glutathione S-transferase theta (hGSTT1) and cell growth more in human colon adenoma (LT97) than tumor (HT29) cells. J Cancer Res Clin Oncol 131:692-700

45. Schlörmann W, Naumann S, Renner C, Glei M (2015) Influence of miRNA-106b and miRNA-135a on butyrate-regulated expression of p21 and Cyclin D2 in human colon adenoma cells. Genes Nutr 10:50

46. Beyer-Sehlmeyer G, Glei M, Hartmann E, Hughes R, Persin C, Böhm V et al (2003) Butyrate is only one of several growth inhibitors produced during gut flora-mediated fermentation of dietary fibre sources. Br J Nutr 90:1057-1070

47. Barrasa JI, Olmo N, Lizarbe MA, Turnay J (2013) Bile acids in the colon, from healthy to cytotoxic molecules. Toxicol In Vitro 27:964-977

48. Jurek D, Fleckl E, Marian B (2005) Bile acid induced gene expression in LT97 colonic adenoma cells. Food Chem Toxicol 43:87-93

49. Zeng H, Claycombe KJ, Reindl KM (2015) Butyrate and deoxycholic acid play common and distinct roles in HCT116 human colon cell proliferation. J Nutr Biochem 26:1022-1028

50. Schlörmann W, Birringer M, Lochner A, Lorkowski S, Richter I, Rohrer C et al (2016) In vitro fermentation of nuts results in the formation of butyrate and c9, t11 conjugated linoleic acid as chemopreventive metabolites. Eur J Nutr 55:2063-2073

51. Naumann S, Schweiggert-Weisz U, Eglmeier J, Haller D, Eisner $P(2019)$ In vitro interactions of dietary fibre enriched food ingredients with primary and secondary bile acids. Nutrients 11:1424

52. Zeng HW, Umar S, Rust B, Lazarova D, Bordonaro M (2019) Secondary bile acids and short chain fatty acids in the colon: a focus on colonic microbiome, cell proliferation, inflammation, and cancer. Int J Mol Sci 20:1214

53. Borowicki A, Stein K, Scharlau D, Glei M (2010) Fermentation supernatants of wheat (Triticum aestivum L.) aleurone beneficially modulate cancer progression in human colon cells. J Agric Food Chem 58:2001-2007

54. Hu S, Dong TS, Dalal SR, Wu F, Bissonnette M, Kwon JH et al (2011) The microbe-derived short chain fatty acid butyrate targets miRNA-dependent $\mathrm{p} 21$ gene expression in human colon cancer. PLoS ONE 6:e16221

55. Humphreys KJ, Cobiac L, Le Leu RK, Van der Hoek MB, Michael MZ (2013) Histone deacetylase inhibition in colorectal cancer cells reveals competing roles for members of the oncogenic miR17-92 cluster. Mol Carcinog 52:459-474

Publisher's Note Springer Nature remains neutral with regard to jurisdictional claims in published maps and institutional affiliations. 